\title{
Announcements
}

\section{Call For Papers: Legal Issues Involving Children and Families}

Law and Human Behavior invites manuscript submission for a special issue focused on children and families. Plans are for the issue to contain several categories of articles, including:

Empirical investigations of legal issues related to children and families, including the consequences to children and families of involvement in the legal system.

Reviews of bodies of empirical research focused on legal issues related to children and families. Reviews should include clear descriptions of (a) ways in which the research can or should inform forensic practice or public policy, and (b) directions for further research and suggestions for paradigms by which this research could be accomplished.

Descriptions of important or newly emerging legal issues related to children and families. Descriptions should include suggestions for the types of research that could be used to inform policy or practice in these areas and, whenever possible, suggestions for paradigms by which this research could be accomplished. These manuscripts are likely to be briefer than those in the other two categories. Collaborative efforts between psychologists and lawyers are particularly encouraged.

Guest editor for this issue is Jeffrey Haugaard. Four copies of manuscripts, prepared by anonymous review, should be sent to:

\author{
Jeffrey J. Haugaard, Ph.D. \\ Cornell University \\ Department of Human Development \\ Van Rensselaer Hall \\ Ithaca, NY 14853
}

Jeffrey Haugaard's e-mail address is: JJH15@CORNELL.EDU. Manuscripts should be received by December 31, 1999. 